\title{
Review: non-nutritive sucking decreases length of hospital stay in premature infants
}

\author{
Pinelli J, Symington A. Non-nutritive sucking in premature infants. (Cochrane Review, latest version 12 Nov 1998.) In: Cochrane \\ Library. Oxford: Update Software.
}

\section{Question}

Does non-nutritive sucking improve clinical outcomes in premature infants?

\section{Data sources}

Studies were identified by searching Medline and CINAHL (back to 1976) and the Cochrane Controlled Trials Register using the terms infant, premature; intensive care units, neonatal; enteral nutrition; sucking behavior; infant nutrition; gastric emptying; growth; parenteral nutrition; bottle feeding; infant care; infant, low birth weight; somatostatin; crying; oxygen; child development; physical stimulation; taste; infant, newborn; and feeding behavior and the text words "non," "nutritive," and "suck." Bibliographies of articles were reviewed and 2 experts were contacted to identify other published or unpublished studies.

\section{Study selection}

Studies were selected if they were experimental or quasiexperimental trials that compared non-nutritive sucking of a pacifier with no provision of non-nutritive sucking in premature infants ( $<37$ wks gestation) and assessed clinically relevant outcomes (eg, weight gain, length of hospital stay, transition to oral or nipple feedings, heart rate and oxygen saturation, and behaviour).

\section{Data extraction}

Data were extracted on study design and methods, participants, intervention, and outcomes. Articles were assessed for methodological quality (eg, blinding and completeness of follow up).

\section{Main results}

19 studies met the selection criteria, but only randomised trials $(n=13)$ were included in the analysis. Meta-analyses showed that infants provided with non-nutritive sucking had shorter hospital stays $(7 \mathrm{~d}$ less) than infants not provided with non-nutritive sucking, but did not differ for weight gain, heart rate, or oxygen saturation (table).

\section{Conclusion}

Non-nutritive sucking provided to premature infants reduces the length of hospital stay, but does not affect weight gain, energy intake, heart rate, or oxygen saturation.

Non-nutritive sucking v no provision of non-nutritive sucking for premature infants*

\begin{tabular}{lllll}
\hline Outcomes & $\begin{array}{l}\text { Number of } \\
\text { studies }\end{array}$ & $\begin{array}{l}\text { Number of } \\
\text { patients }\end{array}$ & $\begin{array}{l}\text { Weighted mean } \\
\text { difference }\end{array}$ & $95 \%$ CI \\
\hline $\begin{array}{l}\text { Length of } \\
\text { hospital stay }\end{array}$ & 2 & 87 & -7.1 days & -12.6 to -1.7 \\
$\begin{array}{l}\text { Weight gain } \\
\text { Heart rate }\end{array}$ & 3 & 103 & $1.57 \mathrm{~g} /$ day & -0.37 to $3.5 \dagger$ \\
$\begin{array}{l}\text { Oxygen } \\
\text { saturation }\end{array}$ & 3 & 126 & -1.4 beats/minute & -5.9 to $3.1 \dagger$ \\
\hline
\end{tabular}

*All meta-analyses were based on a fixed effects model. Heterogeneity was significant only for the analysis of heart rate.

†Not significant.

Source of funding: no external funding.

For correspondence:Dr Janet Pinelli, School of Nursing,McMaster University, 1200 Main Street West, Hamilton, Ontario L8N 3Z5, Canada. Fax +1 9055700667.

\section{Commentary}

Non-nutritive sucking refers to sucking activity when no fluid or nutrition is delivered to the infant. Delivered via a blind nipple or pacifier, non-nutritive sucking is a clinical intervention used to modulate the behavioural state of preterm infants, purportedly improving transition from gavage to breast or bottle feeding. Non-nutritive sucking has also been promoted as reducing infant (both preterm and full term) distress during painful procedures. ${ }^{1}$ Questions remain, however, about the effectiveness of this intervention.

Pinelli and Symington used a comprehensive search strategy to identify high quality studies evaluating the effectiveness of non-nutritive sucking on various relevant clinical outcomes. The included studies were limited to those that involved preterm infants only, and thus the results may not be relevant to full term infants. None of the studies measured thenegative effects of non-nutritive sucking. Further exploration of the potential negative effects of non-nutritive sucking is warranted given the suggestion that this group of infants may be more susceptible to "nipple confusion." The term nipple confusion refers to an infant's difficulty in achieving the correct latching technique and sucking pattern necessary for successful breast feeding, after exposure to an artificial nipple. ${ }^{2}$

Non-nutritive sucking reduced the length of hospital stay and did not affect various other outcomes. Based on this evidence, nurses in neonatal intensive care units may wish to discuss the introduction of non-nutritive sucking with parents of premature infants. This would be consistent with the increasing utilisation of programmes such as the Newborn Individualized Developmental Care and Assessment Program, ${ }^{3}$ in which clinicians move from protocol based to relationship based care. The premise of such programmes is that individualised caregiving based on an infant's current functioning and developmental goals may influence outcomes such as infant health and development, family adaptation, and hospital costs.

$$
\begin{array}{r}
\text { Linda Johnston, RN, PhD } \\
\text { The Victorian Centre for } \\
\text { Nursing Practice Research and } \\
\text { The Royal Children's Hospital } \\
\text { Melbourne, Australia }
\end{array}
$$

1 Gardner S, Snell B, Lawrence R. Breastfeeding the neonate with special needs. In: Merenstein $\mathrm{G}$, Gardner S, editors. Handbook of neonatal intensive care. Fourth edition. St Louis: Mosby, 1998:772.

2 Neifert M, Lawrence R, Seacat J. Nipple confusion: toward a formal definition. J Pediatr 1995;126:S125-9.

3 Als H, Gilkerson L. The role of relationshipbased developmentally supportive newborn intensive care in strengthening outcome of preterm infants. Semin Perinatol 1997;21:178- 